\title{
A Community Case Study on Geographic, Environmental, and Social Health Disparities in COVID-19 Disease: Yakima, Washington
}

\section{Casey Mace Firebaugh"1, Tishra Beeson'1, Amie Wojtyna1, Lilian Bravo², Teresa Everson², Jaclyn Johnson' ${ }^{1}$, Alberto Saldana ${ }^{1}$}

${ }^{1}$ Department of Health Sciences, Central Washington University, Ellensburg, Washington, USA

${ }^{2}$ Yakima County Health District, Yakima, Washington, USA

Email: macec@cwu.edu

How to cite this paper: Firebaugh, C.M., Beeson, T., Wojtyna, A., Bravo, L., Everson, T., Johnson, J. and Saldana, A. (2020) A Community Case Study on Geographic, Environmental, and Social Health Disparities in COVID-19 Disease: Yakima, Washington. Open Journal of Preventive Medicine, 10, 288-297.

https://doi.org/10.4236/ojpm.2020.1011021

Received: October 20, 2020

Accepted: November 27, 2020

Published: November 30, 2020

Copyright $\odot 2020$ by author(s) and Scientific Research Publishing Inc. This work is licensed under the Creative Commons Attribution International License (CC BY 4.0).

http://creativecommons.org/licenses/by/4.0/

\begin{abstract}
Yakima County, Washington, a rural county with an urban core suffered disproportionately under the conditions presented by the COVID-19 pandemic and summer wildfires of 2020. With an infection rate of over 700 per 100,000 population at the height of the pandemic, the county concurrently experienced 14 consecutive days of an air quality index in the unhealthy to hazardous range in August 2020. This paper examines the contributing socioeconomic, geographic, and environmental vulnerabilities that make Yakima County particularly susceptible to the continuum of expected COVID-19 disease and related outcomes and suggests comprehensive areas of investigation to mitigate its impact on special populations, including Hispanic-Latino communities, agricultural, food production, and other essential workers.
\end{abstract}

\section{Keywords}

COVID-19, Coronavirus, SARS-CoV-2, Air Quality, Hispanic/Latino, Health Disparities

\section{Introduction}

Yakima County, Washington has exhibited the highest COVID-19 (also referred to as Coronavirus, SARS-CoV-2) infection rate among any county on the West Coast of the United States [1], with a peak rate of infection that reached above 700 cases per 100,000 population for a 14-day period during June of 2020 [2]. As a predominantly rural area with a high proportion of agricultural, food production, and other essential workers (63\%) [3] and a much higher proportion (50\%) of Hispanic/Latino individuals and families compared to the Washington State 
average (12\%) [4], the Central Washington region represents a high degree of geographic and sociodemographic vulnerability to risk factors for the spread of COVID-19. Yakima has been ranked as the $5^{\text {th }}$ worst municipality for short-term particle air pollution in the United States [5], placing this region at additional risk for environmental exposures that may exacerbate vulnerability to COVID-19 disease and respiratory outcomes [6]. The following paper outlines the domains of vulnerability in which the Yakima region finds itself considering the COVID-19 pandemic. Subsequently, a discussion of the intersection of these factors is presented as well as areas of investigation and intervention that should occur to address this phenomenon.

\subsection{Geographic Vulnerability}

Yakima County is characterized as a large rural county with an urban core. The Centers for Disease Control and Prevention (CDC) released a statement underscoring the need to explore racial and ethnic minority communities' disproportionate experiences with COVID-19 disease severity due to racial residential segregation, a significant factor in health disparities [7]. Preliminary data suggest that areas with lower income per capita and communities of color in Yakima have experienced disproportionate infection from COVID-19 (Figure 1). The percentage of Hispanic/Latino individuals corresponds with the current map of COVID-19 infections (Figure 2) [3] [8].

Since 1992, the federal Health Resources and Services Administration (HRSA) has designated Yakima County as a Medically Underserved Area (MUA) [9]. The county is also designated as a Health Professional Shortage Area (HPSA) due to the proportion of low-income households, and a relative shortage of primary care providers. The county also achieved HPSA scores indicating mental health and dental health care shortages. In January 2020, one of the county's four hospitals ceased operations of its 150-bed facility after filing bankruptcy the previous year. The Astria Regional Medical Center was a Level III adult trauma center and housed the region's Astria Heart Institute for cardiac care services. As a response to the COVID-19 outbreak, the facility was leased to the State of Washington as a surge capacity location for additional patient volume if needed. The six-month lease ended on September 30, 2020 with no additional plans for use of the facility or resumption of clinical operations outside of the emergency response [10].

\subsection{Sociodemographic Vulnerability}

Compared to the state average (12\%) a higher proportion of the population identifies as Hispanic/Latino (50\%) [4] and 4-in-10 speak a language other than English at home. In addition, nearly $7 \%$ of the Yakima County population identifies as American Indian/Alaska Native [4]. National trends in COVID-19 infections demonstrate higher case counts, complications, and mortality due to COVID-19 disease among Hispanic/Latino populations compared to white populations, with similar trends among indigenous populations [11]. 


\section{Rates of covid-19 across block groups in Yakima County excluding} cases in long-term care facilities (5/18/2020).
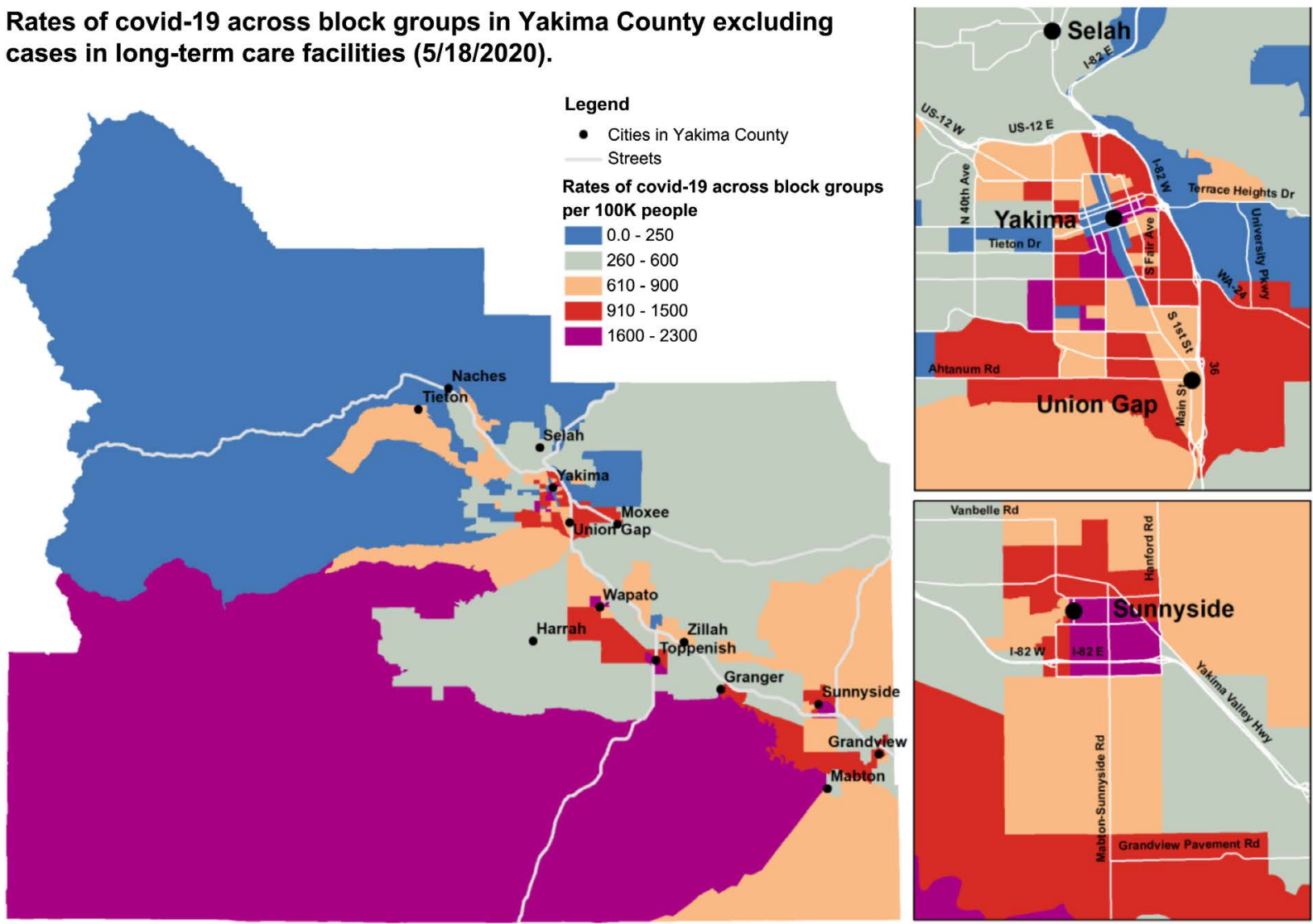

NOTE: Out of the 2,403 confirmed cases of COVID-19, 1,692 were geocoded at the block group level.

Three hundred and eighty-five $(n=385)$ cases were in long-term care facilities.

Three hundred and twenty-six $(n=326)$ cases included a non-geocodable address (i.e., PO Box, an inaccurate address, no address, or were outside of Yakima county).

Figure 1. Geographic distribution of COVID-19 cases in Yakima, county [12].

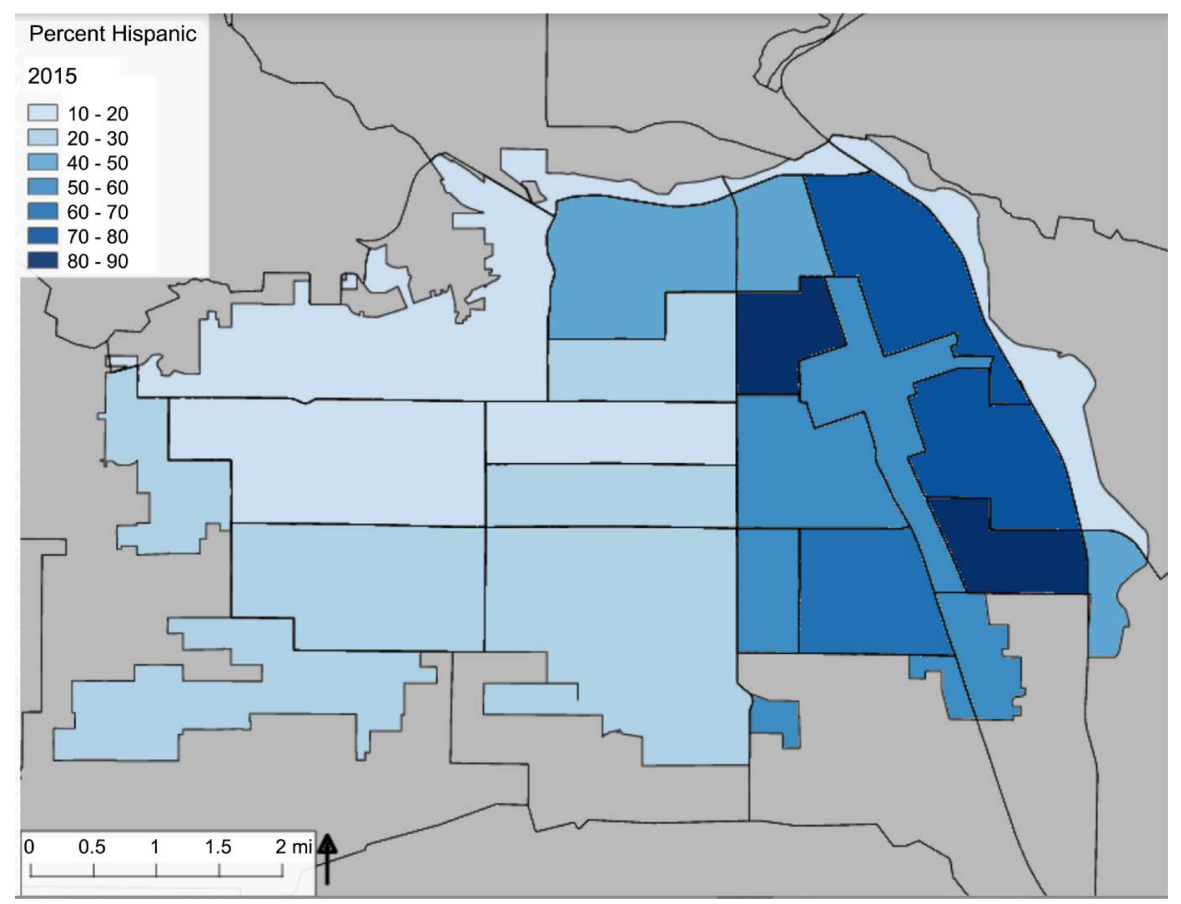

Figure 2. Yakima equity study (2015) Hispanic population geographic distribution [8]. 
As of early May 2020, Yakima County, WA exhibited the highest COVID-19 infection rate among any county on the West Coast of the United States, with 519 cases per 100,000 population [1]. At peak, the county was seeing an average of 148 cases daily, with a case rate above 700 cases per 100,000 population for a 14-day period [2]. Several factors are thought to be responsible for the surge in cases, including cluster outbreaks among agricultural and food production facilities. Over 6-in-10 workers in Yakima County are deemed essential [3], and agricultural industries including fruit-packing, meat-processing and other warehouse functions related to food production comprise a high proportion of jobs in the county (29\%) [13]. Hispanic/Latino populations are significantly more likely to be employed in one of these sectors [14], potentially increasing their risk of exposure to the SARS-CoV2 virus due to their occupation.

As noted in Figure 3, disparities in COVID-19 cases by race/ethnicity are apparent, with $54.4 \%$ of confirmed cases occurring in Hispanic/Latino populations, who comprise approximately $50 \%$ of all Yakima County residents [12]. Those identified as white comprise $42.7 \%$ of the population but only $12 \%$ of cases as of October 2020 [12].

Yakima County also reflects more socioeconomic vulnerability than other counties in Washington State. Inflation-adjusted per-capita income in Yakima County in 2017 was $\$ 41,331$ compared with the state and national per-capita incomes of $\$ 57,896$ and $\$ 51,640$, respectively (6). The poverty rate in Yakima County remains high at $18 \%$, as of 2017 [4], and a stark difference in uninsured status exists within Yakima County at $18 \%$ of adults, compared to only $9 \%$ in Washington State [15]. Yakima County has higher rates of uninsured adults (25.2\%) and children $(5.4 \%)$ compared to both state $(11.8 \%, 3.8 \%)$ and federal $(14.8 \%, 5.7 \%)$ rates of adults children uninsured [16] (Figure 4) Two-thirds (66.6\%) of Yakima County residents are either on Medicaid $49.9 \%$ or Medicare

\section{Race and Ethnicity Breakdown of COVID-19 Positive Individuals}

This table reflects data from $\mathrm{DOH}$ as of $10 / 8 / 20$.

\begin{tabular}{lll}
\hline Race & Percent of Cases & Percent of Yakima County Population* \\
\hline American Indian or Alaska Native & $3.9 \%$ & $6.5 \%$ \\
\hline Asian & $0.4 \%$ & $1.6 \%$ \\
\hline Black or African American & $0.4 \%$ & $1.5 \%$ \\
\hline Hispanic or Latino & $54.4 \%$ & $49 . \%$ \\
\hline Native Hawaiian or Pacific Islander & $0.1 \%$ & $0.3 \%$ \\
\hline Other & $3.1 \%$ & $2.9 \%$ \\
\hline White & $13.5 \%$ & $42.7 \%$ \\
\hline (Missing) & $24.2 \%$ & - \\
\hline Total Number of Cases & 11.906 & $100 \%$
\end{tabular}

"Based on 2019 U.S. Census Bureau Data

Figure 3. COVID-19 cases by race/ethnicity, Yakima county [14]. 
Uninsured Population Age18-64, Percent by Year $^{1}$

\begin{tabular}{l|c|c|c|c|c|c} 
& 2012 & 2013 & 2014 & 2015 & 2016 & 2017 \\
\hline Yakima County & $35.2 \%$ & $37.0 \%$ & $34.9 \%$ & $31.5 \%$ & $28.7 \%$ & $25.2 \%$ \\
\hline Washington State & $18.6 \%$ & $19.2 \%$ & $18.1 \%$ & $16.1 \%$ & $13.9 \%$ & $11.8 \%$ \\
\hline United States & $20.4 \%$ & $20.6 \%$ & $19.8 \%$ & $18.1 \%$ & $16.4 \%$ & $14.8 \%$ \\
\hline
\end{tabular}

Uninsured Population Under Age 18, Percent by Year $^{1}$

\begin{tabular}{l|c|c|c|c|c|c} 
& 2012 & 2013 & 2014 & 2015 & 2016 & 2017 \\
\hline Yakima County & $14.5 \%$ & $12.5 \%$ & $10.0 \%$ & $7.3 \%$ & $6.1 \%$ & $5.6 \%$ \\
\hline Washington State & $6.5 \%$ & $6.1 \%$ & $5.6 \%$ & $4.9 \%$ & $4.3 \%$ & $3.8 \%$ \\
\hline United States & $8.1 \%$ & $7.6 \%$ & $7.1 \%$ & $6.5 \%$ & $5.9 \%$ & $5.7 \%$ \\
\hline
\end{tabular}

Figure 4. Uninsured population Yakima, Washington [16].

$16.7 \%$. In addition, $42.4 \%$ of the population is receiving some financial assistance in the form of child support services; childcare; and basic food programs [16].

Although the Yakima Health District worked with the Washington State Department of Health to provide completely free testing via community-based test sites [2], it is not yet clear what the costs or other barriers for testing have been for those who are uninsured, going through primary care providers, or other venues for testing.

\subsection{Environmental Vulnerability}

The American Lung Association recently ranked Yakima as the 5th worst city and $13^{\text {th }}$ worst county for short-term particle pollution and $27^{\text {th }}$ for annual particle pollution [5] [17]. The target region has experienced notable deficits in air quality over the past decade, determined by observed fine particulate matter $\left(\mathrm{PM}_{2.5}\right)$ [17] [18]. $\mathrm{PM}_{2.5}$ is defined as all particulate matter that is smaller in aerodynamic diameter than $2.5 \mu \mathrm{m}$. Upon inhalation, it has been found to impact human health, in particular the respiratory and cardiovascular systems, and to cause premature death [19]. $\mathrm{PM}_{2.5}$ is mainly made up of products from combustion processes (e.g., motor vehicles, power plants, wood burning, etc.) and some industrial activities [19]. Air quality in the area has declined in recent years, $\mathrm{PM}_{2.5}$ concentrations reached unhealthy levels of $>20 \mu \mathrm{g} \cdot \mathrm{m}^{-3}$ on average 20 days per year during winter months and up to 31 days during summer in the target region. Because of climate change, characterized by increasing temperatures and drier conditions, wildfires are expected to become part of a typical summer season. Current climate change models forecasting until 2040 project that approximately 1.1 million acres of Washington forests will burn per year, which will significantly impact air quality in the region [18]. Recent air quality episodes are directly related to wildfire events and have led to $\mathrm{PM}_{2.5}$ concentrations that far exceeded the national 24-hr Environmental Protection Agency (EPA) standard of $35 \mu \mathrm{g} \cdot \mathrm{m}^{-3}$, peaking at $250-300 \mu \mathrm{g} \cdot \mathrm{m}^{-3}$. [18] [20]. Given the strong seasonality of climate and air quality characteristics in Yakima County, it is expected that these environmental exposures may correspond directly to pulmonary function and risk factors for COVID-19 as respiratory infectious disease, among other comorbidities including cardiovascular disease, chronic obstructive pulmonary disorder (COPD), childhood and adult asthma, and others. During the summer 2020 period, several wildfires have erupted in the Washing- 
ton, Oregon, and California region resulting in a significant number of days (15 or more) with hazardous levels of smoke [21] (Figure 5). It is not yet clear what the health impacts of this severe wildfire event have been specifically, considering the COVID-19 pandemic

\section{The Interaction of COVID-19 Disease Vulnerabilities}

Residents of Yakima County, Washington are subject to multiple risk factors for poor outcomes related to COVID-19 disease, most notably respiratory complications and mortality. Recent reports suggest a recovery period of 3 - 12 months for survivors of the COVID-19 disease to fully regain lung function [22]. The smoke and wildfire season of 2020 has elevated respiratory health risk factors for all residents, aside from COVID-19 disease-a pattern that is expected to persist in coming years. The seasonal environmental exposures to poor air quality, the high prevalence of COVID-19 disease, and the concentration of these COVID-19 infections in socially-vulnerable communities including agricultural farmworkers and other essential service staff such as warehouse workers and temporary workers living in congregate living situations, non-White, non-English speaking populations, present a perfect storm of vulnerabilities that may heighten the worst outcomes of COVID-19 disease in this community. While behavioral interventions such as the use of facial coverings, monitoring symptoms, hand hygiene and physical distancing are proven to minimize community transmission of COVID-19, these behaviors may be particularly challenging for certain subgroups who traditionally face these vulnerabilities at disproportionate rates. Moreover, the outdoor air quality and wildfire events have further complicated the behavioral tools we have to fight COVID-19. For example, expert recommendations have consistently suggested that outdoor gatherings bear lower risk

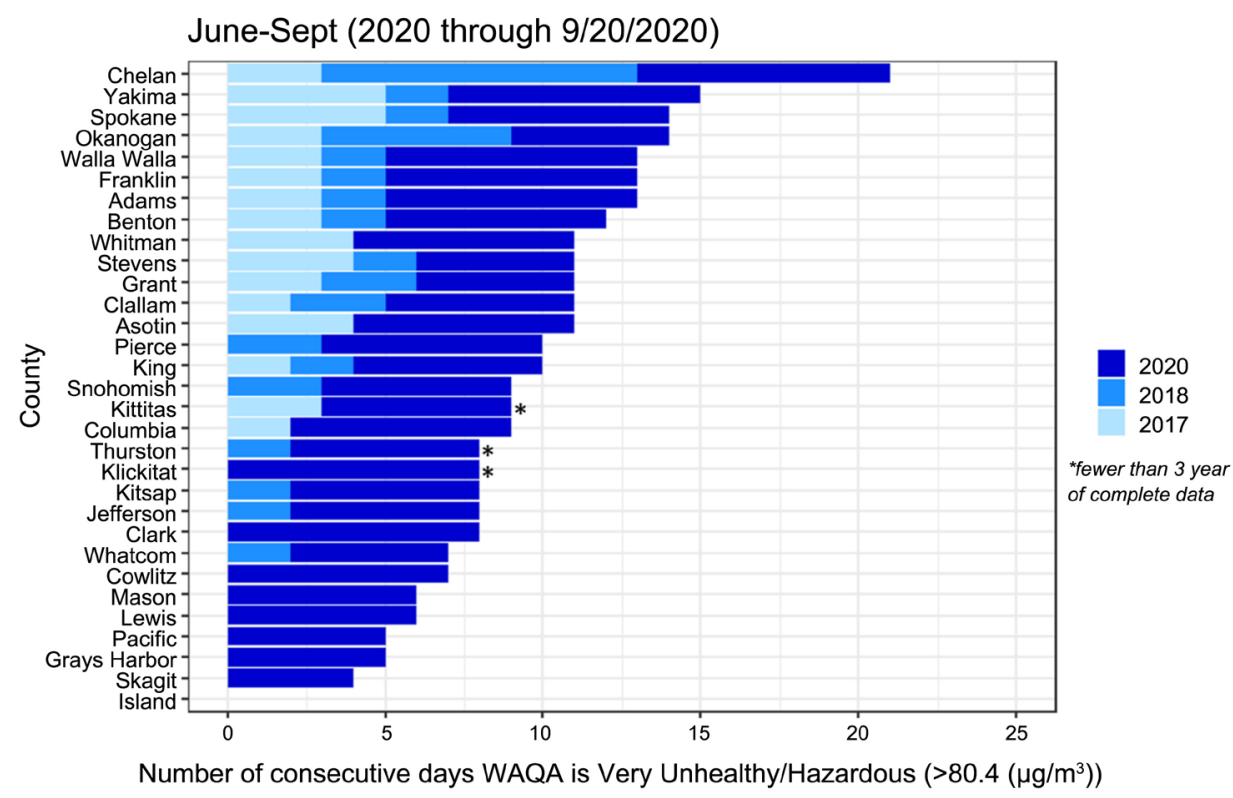

Figure 5. Washington state air quality summer 2020 [21]. 
for transmission of the SARS-CoV2 virus [23] yet at least two weeks of unhealthy air quality in Yakima County during the July-September 2020 period [24] may have motivated many individuals to stay indoors during a time when COVID-19 disease transmission was still high. And it has previously been advised by local and state health departments that any outdoor workers be equipped with N-95 or N-100 masks or other appropriate PPE [25]. Yakima Health District provided $>8000 \mathrm{~N}-95$ masks for agricultural workers, and the Washington Tree Fruit Association reportedly provided 100,000 across the state [2]. Some operations also ceased for several days while smoke was greatest [2]. While data is still emerging on COVID-19 disease transmission trends during the wildfire season of 2020, we suggest systematic investigation of these trends as outdoor air quality events intersect with the pandemic nature of COVID-19.

\section{Implications for Practice}

A multi-faceted population health strategy should be implemented to 1) address poor air quality, and 2) prevent COVID-19 disease transmission through community mitigation strategies, and 3) reduce health disparities for vulnerable populations. Each of these factors should be understood on their own and in respect to one another.

We recommend a substantial effort to investigate the intersection of these vulnerabilities to COVID-19 disease outcomes in Yakima County through the following areas of inquiry including but not limited to:

- Investigation of household risk and prevention behaviors related to minimizing community transmission of the SARS-CoV2 virus. This will include an analysis of risk profiles and behavioral tools such as handwashing, wearing facial coverings, and physical distancing, knowledge and attitudes about such prevention strategies, and special attention to the social determinants of health that may make these strategies more difficult to adopt among vulnerable populations;

- Investigation of barriers to isolation and quarantine like economic hardship/need to work;

- Investigation of factors impacting beliefs/behaviors around COVID-19 disease such as political beliefs or trust in public health/healthcare community;

- Monitoring of indoor and outdoor air quality for the potential impact of susceptibility and severity of COVID-19 disease along with the recovery of COVID-19 disease survivors related to these exposures;

- Examination of socio-ecological factors beyond the individual, household or even community control in both trying to prevent and respond to these challenges, these include policies, social, and environmental factors.

\section{Limitations}

This study is not meant to be conclusive in nature but rather serves as an outline of the various factors requiring further examination on this emerging public 
health issue. This study has presented a series of patterns and factors for the consideration of the public health community as investigation into the emerging COVID-19 pandemic continues.

\section{Conclusion}

The phenomenon of the COVID-19 pandemic and the summer fires of 2020 in the Pacific Northwest on a geographically and socially vulnerable population highlights the complexity of today's public health challenges. Natural disasters such as fires and pandemics are predictable only in the fact that they will occur. Given the complexity of these challenges, response and intervention must go beyond focusing on individual behavior change. These circumstances demand environmental, structural, social, and policy level responses to support any individual or community interventions. Rural communities face several challenges in responding to these events, in particular when disparities pre-exist and the events are simultaneously affecting communities with higher populations. As the COVID-19 pandemic unfolds, our rural communities and particularly our communities of color in rural areas must not be forgotten in the public health response.

\section{Conflicts of Interest}

The authors declare no conflicts of interest regarding the publication of this paper.

\section{References}

[1] Geranios, N.K. (2020) County Has Highest Rate of COVID-19 Cases on West Coast. The Seattle Times. https://www.seattletimes.com/seattle-news/yakima-county-has-top-rate-of-coronav irus-cases-on-west-coast/

[2] Everson, T. (2020) Interviewee, Yakima County Case Rates During COVID-19. [Interview].

[3] Yakima County Health District (2020) Yakima County Health District: COVID-19 Data Summary. https://www.yakimacounty.us/2404/Data-Summary

[4] United States Census Bureau (2019) Census Quick Facts-Yakima County, Washington.

https://www.census.gov/quickfacts/yakimacountywashington

[5] American Lung Association (2020) Nearly Half of U.S. Breathing Unhealthy Air; Record-Breaking Air Pollution in Nine Western Cities. https://www.lung.org/media/press-releases/state-of-the-air-2020

[6] Wu, X., Nethery, R.C., Sabath, B.M., Braun, D. and Dominici, F. (2020) Exposure to Air Pollution and COVID-19 Mortality in the United States. medRxiv. https://doi.org/10.1101/2020.04.05.20054502

[7] Centers for Disease Control and Prevention (2020) COVID-19 in Racial and Ethnic Minority Groups.

https://www.cdc.gov/coronavirus/2019-ncov/need-extra-precautions/racial-ethnicminorities.html 
[8] Hurvitz, P. (2017) Yakima Equity Study Appendix A: GIS Analysis. https://www.yakimawa.gov/apps/equity-study-analysis/\#32_historical_demograpics

[9] Health Services and Resource Center (2020) HSRA Data Warehouse. https://data.hrsa.gov/tools/shortage-area/hpsa-find

[10] Hoang, M. (2020) Plans Call for Using a STRIA Regional for Non-COVID-19 Patients.

https://www.yakimaherald.com/special_projects/coronavirus/plans-call-for-using-a stria-regional-for-non-covid-19-patients/article_0e383f7a-7301-576d-9203-898fe47 24fda.html

[11] Centers for Disease Control and Prevention (2020) COVID-19 Hospitalization and Death by Race/Ethnicity.

https://www.cdc.gov/coronavirus/2019-ncov/covid-data/investigations-discovery/h ospitalization-death-by-race-ethnicity.html

[12] Yakima Health District (2020) Confirmed Cases, Race \& Ethnicity. https://www.yakimacounty.us/2440/Confirmed-Cases-Race-EthnicityEmployment

[13] Security Deparment Washington State (2019) Yakima County Profile. https://esd.wa.gov/labormarketinfo/county-profiles/yakima

[14] U.S. Bureau of Labor Statistics (2020) Quarterly Census of Employment and Wages. https://esd.wa.gov/labormarketinfo/county-profiles/yakima

[15] County Health Rankings and Roadmaps (2020) Yakima, Washington. https://www.countyhealthrankings.org/app/washington/2020/rankings/yakima/cou nty/outcomes/overall/snapshot

[16] Yakima Mason Memorial (2019) Community Health Needs Assessment. Yakima Mason Memorial, Yakima.

[17] American Lung Association (2019) State of the Air. American Lung Association, Chicago.

[18] Washington Department of Ecology (2020) Wildfire Information. https://ecology.wa.gov/Air-Climate/Air-quality/Smoke-fire/Wildfires

[19] Environmental Protection Agency (2017) Health and Environmental Effects of Particulate Matter (PM).

https://www.epa.gov/pm-pollution/health-and-environmental-effects-particulate-m atter-pm

[20] Environmental Protection Agency (2016) NAAQS Table. https://www.epa.gov/criteria-air-pollutants/naaqs-table

[21] Washington Smoke Information (2020) Smoky Siege: A Look Back at the Smoke Storm of 2020.

https://wasmoke.blogspot.com/2020/09/smoky-siege-look-back-at-smoke-storm-of. $\underline{\mathrm{html}}$

[22] Galiatsatos, P. (2020) What Coronavirus Does to the Lungs.

https://www.hopkinsmedicine.org/health/conditions-and-diseases/coronavirus/wha t-coronavirus-does-to-the-lungs

[23] Freeman, S. and Eykelbosh, A. (2020) COVID-19 and Outdoor Safety: Considerations for Use of Outdoor Recreational Spaces. National Collaborating Centre for Environmental Health, Vancouver.

[24] Washington Smoke Information (2020) The Worst Is behind Us but It Ain't Over Yet.

https://wasmoke.blogspot.com/2020/09/the-worst-is-behind-us-but-it-aint-over.ht $\underline{\mathrm{ml}}$ 
[25] State of California Department of Industrial Relations (2020) Protecting Outdoor Workers Exposed to Smoke from Wildfires.

https://www.dir.ca.gov/dosh/wildfire/worker-protection-from-wildfire-smoke.html 